\title{
Resistin, Visfatin, Adiponectin, and Leptin: Risk of Breast Cancer in Pre- and Postmenopausal Saudi Females and Their Possible Diagnostic and Predictive Implications as Novel Biomarkers
}

\author{
Adel M. A. Assiri, ${ }^{1}$ Hala F. M. Kamel, ${ }^{1,2}$ and Mohamed F. R. Hassanien ${ }^{3}$ \\ ${ }^{1}$ Biochemistry Department, Faculty of Medicine, Umm Al-Qura University, Makkah, Saudi Arabia \\ ${ }^{2}$ Medical Biochemistry Department, Faculty of Medicine, Ain Shams University, Cairo, Egypt \\ ${ }^{3}$ Institute of Scientific Research and Revival of Islamic Heritage, Umm Al-Qura University, Makkah, Saudi Arabia \\ Correspondence should be addressed to Hala F. M. Kamel; kamelhala@msn.com
}

Received 20 December 2014; Accepted 12 February 2015

Academic Editor: Claudio Letizia

Copyright ( $) 2015$ Adel M. A. Assiri et al. This is an open access article distributed under the Creative Commons Attribution License, which permits unrestricted use, distribution, and reproduction in any medium, provided the original work is properly cited.

\begin{abstract}
The mechanisms of obesity-induced breast carcinogenesis are not clear. One hypothesis is that high levels of adipokines could promote breast cancer $(\mathrm{BC})$ development. The aim of this study was to investigate the correlation of resistin, visfatin, adiponectin, and leptin with BC risk in pre- and postmenopausal females. A total of $82 \mathrm{BC}$ newly diagnosed and histologically confirmed patients and 68 age and BMI matched healthy controls were enrolled. Both groups were subdivided into post- and premenopausal subgroups. Resistin, visfatin, adiponectin, and leptin were measured by ELISA. There were significantly higher levels of leptin, resistin, and visfatin in postmenopausal BC patients than their respective controls. Only in postmenopausal subgroups, leptin, resistin, and visfatin levels were positively correlated with TNM staging, tumor size, lymph node (LN) metastasis, and histological grading. In postmenopausal females, multivariate logistic regression analysis revealed that adiponectin, leptin, visfatin, and resistin were risk factors for BC. Our results suggested that serum resistin, leptin, adiponectin, and visfatin levels as risk factors for postmenopausal $\mathrm{BC}$ may provide a potential link with clinicopathological features and are promising to be novel biomarkers for postmenopausal BC.
\end{abstract}

\section{Introduction}

Studies indicated that obesity, as reflected by increased body mass index (BMI), is associated with increased risk of more aggressive $\mathrm{BC}[1,2]$. Obese women are likely to have metastatic BC when they are first diagnosed and to have a poor prognosis regardless of their menopausal status $[3,4]$. Accumulating evidence suggests that adipose tissue, as an endocrine organ producing and secreting a large range of factors, may interfere with cancer development. These factors, called adipokines, involved in the mediation of inflammatory diseases and obesity $[5,6]$. Adipokines, as leptin, adiponectin, visfatin, and resistin, are produced by different fat depots, including subcutaneous, visceral, and mammary adipose tissues. It is worth noting that adipokines may act on breast tissue in an endocrine manner, in a paracrine pathway, and in an autocrine action $[7,8]$. The structure of the mammary gland may be in favor of close interaction between mammary adipose tissue and breast tissue, which suggests that adipokines produced by mammary adipose tissue and the tumor cell microenvironment may be the major link between obesity and $\mathrm{BC}$ progression and metastasis $[9,10]$.

Obesity has effects on a number of hormones and growth factors potentially linked to BC. A major cluster of obesity-related metabolic consequences include altered concentrations of circulating adipocytokines and development of insulin resistance including hyperinsulinaemia and impaired glucose metabolism [11]. The most prominent adipokine, 
leptin, was first described as a neurohormone whose primary function is to regulate energy balance and food intake in the hypothalamus. Subsequent studies found that leptin can modulate several processes in the peripheral organs, such as immune response, fertility, and hematopoiesis. On a cellular level, leptin has been found to act as a mitogen, metabolic regulator, motogenic, and proangiogenic factor [12]. New evidence suggests that leptin could be involved in tumorigenesis, especially in the development of breast, colorectal, and prostate cancers [13]. In several BC cell models, leptin has been shown to induce proliferation, survival, and anchorage-independent growth. These leptin activities are mediated through the long/signaling form of the leptin receptor (ObRL) that, upon leptin binding, can stimulate the Jak/STAT3, ERK1/2, and phosphoinositide 3kinase pathways as well as inducing cyclin D1 expression and retinoblastoma protein hyperphosphorylation $[14,15]$. Adiponectin is another adipocyte-derived peptide hormone that is inversely associated with adiposity [16]. Adiponectin is a strong indicator of insulin sensitivity wherein its decline precedes the onset of obesity and insulin resistance [17] and may be one mechanism through which obesity alters $\mathrm{BC}$ risk. Mantzoros et al. [18] found an inverse association between serum adiponectin levels and BC risk among postmenopausal women.

Resistin, named for resistance to insulin, is a unique signaling molecule secreted from adipocytes. Resistin may serve as a hormone that potentially links obesity to insulin resistance [19]. High level of resistin was reported to be associated with the risk of $\mathrm{BC}$, wherein this relationship was independent of age, BMI, status of menopause, serum glucose, and adiponectin [20]. Visfatin, also known as pre$\mathrm{B}$ cell colony-enhancing factor, is a novel adipokine, found in the visceral fat. Visfatin plays an important role in a variety of metabolic and stress responses as well as in the cellular energy metabolism as Nampt (nicotinamide phosphoribosyltransferase) [21]. Interestingly, it was shown that serum visfatin is significantly elevated in patients with gastric carcinoma and $\mathrm{BC}$ and may be a promising biomarker for colorectal adenocarcinoma [22]. High expression of visfatin in BC tissues was reported to be associated with more malignant cancer behavior as well as adverse prognosis [23]. Epidemiologic studies have demonstrated that age, hormone-associated reproductive factors such as earlier age at menarche, later age at menopause, anthropometric characteristics such as $\mathrm{BMI}$, and waist circumference (WC) are well-established risk factors for BC $[24,25]$.

Recent studies have shown that the constellation of obesity, insulin resistance, and serum adipocytokine levels is associated with the risk and prognosis of $\mathrm{BC}$, especially postmenopausal breast cancer (PBC) [26, 27]. However, the exact mechanisms responsible for the complexity of the effect of obesity and various adipokines on BC risk in pre- and postmenopausal women need to be elicited. We aimed in our study to investigate the correlation of resistin, visfatin, adiponectin, and leptin with $\mathrm{BC}$ risk in pre- and postmenopausal females and to evaluate their relation to other metabolic, anthropometric measures with different clinicopathological features of BC.

\section{Materials and Methods}

2.1. Study Populations. Population enrolled in this study was 150 Saudi females. BC patients $(n=82)$ were newly diagnosed and histologically confirmed BC with no prior surgical, chemotherapy, or radiotherapy BC treatment, who attended King Abdulla Medical City or El-Noor Hospital (Makkah, KSA) from March 2011 till December 2013. Healthy control subjects $(n=68)$ were age and BMI matched with BC group. Both groups were subdivided into two subgroups according to menopausal status. Women $(n=41$, healthy control and 38 cases) were considered postmenopausal at the time of blood collection (if they had no menstrual cycles in the last 12 months). Women ( $n=44$, cases and 27 controls) were defined as premenopausal at blood draw (if reported that their periods had not ceased and were 45 years or younger). Once patients and control subjects agreed to participate, written informed consent was obtained. For all subjects, comprehensive questionnaires were used to collect medical information. Complete history was obtained including menstrual and reproductive history, menopausal status, lifestyle behaviors, and medical history as well as family history of BC and other cancers. Because questionnaire data and specimens were obtained prior to cases' acceptance with surgery and radio- or chemotherapy, any influence of treatment was unlikely. All cases and controls who participated in our study were fully informed of the aim of the study and gave written consent for their participation. The study was approved by the Faculty of Medicine Ethics Review Board for Human Studies at Umm Al-Qura University (Makkah, KSA).

\subsection{Anthropometric Measurements and Clinical Examina-} tion. For all participants physical, clinical examinations and anthropometric measurements were performed. Height (to the nearest $0.5 \mathrm{~cm}$ ) and weight (to the nearest $0.1 \mathrm{~kg}$ ) were measured. BMI was calculated as weight in $\mathrm{kg}$ divided by the square of height in meters. Waist circumference was measured using a standardized measuring tape in $\mathrm{cm}$, in addition to systolic and diastolic blood pressure measurements. All control subjects were confirmed free from benign or malignant breast diseases by physical examination and mammography. Women with history or family history of any tumor or cancer were excluded. Diagnosis of BC was confirmed histologically in each case and estrogen receptor statues were determined. The staging of $\mathrm{BC}$ was determined according to the TNM system.

2.3. Laboratory Measurements. Blood samples were collected from study subjects after overnight fasting for $12 \mathrm{~h}$ using $B D$ vacutainer serum tubes. Samples were transported in portable insulated bags containing ice packs $\left(0-4^{\circ} \mathrm{C}\right)$ and processed by centrifugation at $1467 \mathrm{~g}$ for $10 \mathrm{~min}$ at room temperature within $6 \mathrm{~h}$ of collection. Plasma, buffy coat, and red blood cells were separated and stored at $-70^{\circ} \mathrm{C}$ until subsequent analysis. The concentration of leptin $(\mathrm{ng} / \mathrm{mL})$ was determined using ELISA kits (Millipore, Missouri, USA). The concentration of total adiponectin $(\mathrm{ng} / \mathrm{mL})$ was determined using sandwich ELISAs with kits (ALPCO Diagnostics, 
North Carolina, USA). The total adiponectin values in this study represented measurements of trimer, hexamer, and high molecular weight (HMW) forms of adiponectin in blood. Serum visfatin levels $(\mathrm{ng} / \mathrm{mL})$ were measured using a commercial enzyme immunoassay kit (Phoenix Pharmaceuticals, Belmont, CA, USA). Resistin $(\mu \mathrm{g} / \mathrm{L})$ was determined by immunosorbent assays (ELISA, R\&D systems Inc., USA). All samples were assayed in duplicate and completely blinded to the clinical information. All procedures in the manufacturer's instructions were followed, and quality control measurements were within the ranges recommended by the manufacturer. The minimum detectable concentration for the leptin kit was $0.25 \mathrm{ng} / \mathrm{mL}$, and its intra-assay and interassay coefficients of variation (CVs) ranged from $3.0 \%$ to $6.2 \%$. The minimum detectable concentration for the adiponectin kit was $0.15 \mathrm{ng} / \mathrm{mL}$, wherein its intra-assay and interassay coefficient of variation (CVs) ranged from $2.9 \%$ to $6.6 \%$. The minimum detectable concentration for visfatin assay was $0.1 \mathrm{ng} / \mathrm{mL}$, with an intra-assay coefficient of variation $5.2 \%$ and an interassay coefficient of variation $5.8 \%$. The intra- and interassay coefficients of variation were $5.2 \%$ and $7.8 \%$ for resistin. Fasting blood glucose $(\mathrm{mg} / \mathrm{dL})$ was determined using a glucose oxidase assay and the serum concentrations of LDLc (mg/dL). Total cholesterol TC in mg/dL, HDLc (mg/dL), and triglycerides $(\mathrm{mg} / \mathrm{dL})$ were determined using colorimetric enzyme kits (Spinreact, Bas Gerona, Spain).

2.4. Statistical Analysis. Data were analyzed with the IBM Statistical Package for the Social Sciences SPSS version 20.0. Descriptive data were given as mean \pm standard deviation (SD). Comparison between the two groups was performed with $t$-test and covariance analysis, whereas comparisons among subgroups were performed using ANOVA test. Post hoc pairwise comparisons were performed using the Bonferroni method. The Pearson correlation coefficients $(r)$ were used as measurements of correlation for continuous normally or not normally distributed variables, respectively. The relationships clinic-pathological characters of $\mathrm{BC}$ cases (TNM, tumor size, LN, and histological grade) and variables were analyzed by linear correlation and stepwise regression. The logistic multivariant regression analysis was used to analyze the relationship between adipocytokines, metabolic factors, and risk of LN metastasis of BC. $P$ value less than 0.05 was considered statistically significant.

\section{Results}

The baseline characteristics of all subjects are summarized in Table 1 . The mean age $( \pm \mathrm{SD})$ of the cases and controls was 53.68 and 52.25 years, respectively, and there was no statistical difference between them $(P=0.567)$. BC patients showed higher WC than control subjects $(P=0.026)$. Meanwhile, systolic and diastolic blood pressure showed no significant difference between both groups $(P=0.096$ and 0.147$)$, respectively.There were higher levels of metabolic parameters including TG, TC, and LDLc among BC patients than controls $(P=0.000)$, while HDLc levels were significantly lower in controls than cancer patients $(P=0.000)$.
TABLE 1: The characteristic features, metabolic, and adipokines levels of healthy control and BC group.

\begin{tabular}{lccc}
\hline & $\begin{array}{c}\text { Healthy control } \\
(n=68)\end{array}$ & $\begin{array}{c}\text { Breast cancer } \\
(n=82)\end{array}$ & $P$ value \\
\hline Age $($ years $)$ & $52.25 \pm 16.62$ & $53.682 \pm 13.98$ & 0.567 \\
BMI $\left(\mathrm{kg} / \mathrm{m}^{2}\right)$ & $24.84 \pm 1.35$ & $24.59 \pm 1.48$ & 0.062 \\
WC $(\mathrm{cm})$ & $76.34 \pm 3.05$ & $77.52 \pm 3.34$ & $0.026^{*}$ \\
SBP $(\mathrm{mmHg})$ & $124.79 \pm 9.21$ & $127.52 \pm 10.52$ & 0.096 \\
DBP $(\mathrm{mmHg})$ & $83.01 \pm 7.98$ & $80.85 \pm 9.83$ & 0.147 \\
Glucose $(\mathrm{mg} / \mathrm{dL})$ & $92.42 \pm 12.39$ & $94.80 \pm 13.51$ & 0.076 \\
TG $(\mathrm{mg} / \mathrm{dL})$ & $123.38 \pm 27.403$ & $152.60 \pm 22.60$ & $0.000^{*}$ \\
TC $(\mathrm{mg} / \mathrm{dL})$ & $192.53 \pm 17.718$ & $216.52 \pm 28.82$ & $0.000^{*}$ \\
LDLc $(\mathrm{mg} / \mathrm{dL})$ & $131.43 \pm 23.29$ & $145.06 \pm 21.32$ & $0.000^{*}$ \\
HDLc $(\mathrm{mg} / \mathrm{dL})$ & $45.47 \pm 5.41$ & $40.36 \pm 4.38$ & $0.000^{*}$ \\
Leptin $(\mathrm{ng} / \mathrm{mL})$ & $19.62 \pm 2.03$ & $24.59 \pm 5.57$ & $0.000^{*}$ \\
Adiponectin $(\mathrm{mg} / \mathrm{L})$ & $10.96 \pm 1.60$ & $8.44 \pm 2.12$ & $0.000^{*}$ \\
Resistin $(\mu \mathrm{g} / \mathrm{L})$ & $22.69 \pm 2.58$ & $26.24 \pm 1.59$ & $0.000^{*}$ \\
Visfatin $(\mathrm{ng} / \mathrm{mL})$ & $15.57 \pm 2.41$ & $18.36 \pm 3.92$ & $0.000^{*}$ \\
\hline
\end{tabular}

BMI: body mass index; WC: waist circumference; SBP: systolic blood pressure; DBP: diastolic blood pressure; Tc: total cholesterol; ${ }^{*} P<0.05$.

Serum levels of leptin, resistin, and visfatin were significantly higher in BC patients than controls $(P=0.000)$, while adiponectin levels were significantly low $(P=0.000)$ in $\mathrm{BC}$ patients. Interestingly, we found no significant difference between premenopausal BC patients and premenopausal controls for leptin, adiponectin, resistin, and visfatin $(P=$ $0.228,0.59,0.52$, and 0.85 , resp.). Meanwhile, we found significantly higher levels of leptin, resistin, and visfatin $(P=$ $0.000)$ in postmenopausal BC patients than postmenopausal normal controls. Serum adiponectin levels were significantly lower in postmenopausal BC patients than respective controls $(P=0.000)$. Anthropometric measurements showed that WC levels were significantly higher in postmenopausal BC patients than postmenopausal control $(P=0.00)$ and no significant difference was found between premenopausal BC and premenopausal control groups $(P=0.50)$ as shown in Tables 1 and 2 .

Pearson's correlation analysis using anthropometric, metabolic, and adipokines levels among all groups $(n=150)$ and healthy control $(n=68)$ revealed very interesting finding. When applying the test among healthy control group, the studied adipokines levels showed non significant correlation with other metabolic or anthropometric measurements as shown in Table 3. Data reveled that among all groups serum adiponectin levels showed negative correlation with BMI, WC, and TG $(r=-0.232, P=0.004 ; r=-0.295, P=0.000$; and $r=-0.337, P=0.000$, resp.) and positive correlation with HDLc $(r=0.216, P=0.008)$. Serum leptin levels were positively correlated to BMI, WC, DBP, glucose, and TG $(r=$ $0.313, P=0.000 ; r=0.276, P=0.001 ; r=0.187, P=0.022$; $r=0.242, P=0.003$; and $r=0.176, P=0.031$, resp.) but negatively with HDLc $(r=-0.170, P=0.38)$. Serum resistin concentrations were positively correlated to SBP, TG, and TC $(r=0.192, P=0.019 ; r=0.185, P=0.023$; and $r=0.316$, $P=0.000$, resp.) but negatively to HDLc $(r=-0.281$, 
TABLE 2: Anthropometric measurements, metabolic, and adipokines serum levels among all groups.

\begin{tabular}{|c|c|c|c|c|}
\hline & \multicolumn{2}{|c|}{ Premenopause } & \multicolumn{2}{|c|}{ Postmenopause } \\
\hline & $\begin{array}{l}\text { Healthy control } \\
\qquad(n=27)\end{array}$ & $\begin{array}{l}\text { Breast cancer } \\
\quad(n=44)\end{array}$ & $\begin{array}{l}\text { Healthy control } \\
\qquad(n=41)\end{array}$ & $\begin{array}{c}\text { Breast cancer } \\
\quad(n=38)\end{array}$ \\
\hline Age (years) & $35.22 \pm 7.59$ & $43.68 \pm 6.07^{\mathrm{a}}$ & $63.46 \pm 10.04$ & $65.26 \pm 11.34^{\mathrm{a}}$ \\
\hline BMI $\left(\mathrm{kg} / \mathrm{m}^{2}\right)$ & $23.72 \pm 1.26$ & $24.04 \pm 1.24$ & $24.22 \pm 1.42$ & $24.92 \pm 1.51$ \\
\hline $\mathrm{WC}(\mathrm{cm})$ & $76.71 \pm 2.91$ & $76.21 \pm 3.39$ & $76.09 \pm 3.15$ & $79.05 \pm 2.59^{\mathrm{a}}$ \\
\hline SBP (mmHg) & $123.29 \pm 9.31$ & $124.43 \pm 7.42$ & $125.78 \pm 9.08$ & $131.10 \pm 12.42^{\mathrm{a}}$ \\
\hline DBP (mmHg) & $77.37 \pm 8.0$ & $79.11 \pm 9.06$ & $82.73 \pm 5.44$ & $86.11 \pm 10.40^{\mathrm{a}}$ \\
\hline Glucose (mg/dL) & $88.02 \pm 10.39$ & $88.80 \pm 12.51$ & $98.56 \pm 11.68$ & $98.60 \pm 12.51$ \\
\hline $\mathrm{TG}(\mathrm{mg} / \mathrm{dL})$ & $118.27 \pm 29.97$ & $151.50 \pm 19.60$ & $126.57 \pm 25.37$ & $153.88 \pm 26.20$ \\
\hline TC (mg/dL) & $189.14 \pm 23.17$ & $204.52 \pm 23.82$ & $194.76 \pm 12.718$ & $224.52 \pm 30.82$ \\
\hline LDLc (mg/dL) & $121.56 \pm 19.55$ & $142.94 \pm 23.27$ & $137.93 \pm 23.49$ & $147.52 \pm 18.82$ \\
\hline HDLc (mg/dL) & $44.81 \pm 5.37$ & $39.91 \pm 4.83$ & $45.90 \pm 5.41$ & $40.89 \pm 3.78$ \\
\hline Leptin (ng/mL) & $19.52 \pm 2.93$ & $20.32 \pm 1.87$ & $19.68 \pm 1.19$ & $29.52 \pm 4.17$ \\
\hline Adiponectin (mg/L) & $10.86 \pm 1.67$ & $9.92 \pm 0.62$ & $11.01 \pm 1.58$ & $6.74 \pm 1.92$ \\
\hline Resistin $(\mu \mathrm{g} / \mathrm{L})$ & $24.15 \pm 1.24$ & $25.21 \pm 1.54$ & $21.73 \pm 2.79$ & $27.14 \pm 1.79$ \\
\hline Visfatin (ng/mL) & $15.03 \pm 2.91$ & $16.96 \pm 1.99$ & $15.26 \pm 2.41$ & $21.20 \pm 3.62$ \\
\hline
\end{tabular}

${ }^{\mathrm{a}} P<0.05$ as calculated by ANOVA $t$-test versus respective controls (between premenopausal healthy control and premenopausal BC patients and between postmenopausal healthy control and postmenopausal BC patients).

TABLE 3: Pearson's correlation analysis using different variables between all groups and healthy control group.

\begin{tabular}{|c|c|c|c|c|c|c|c|c|c|c|c|c|}
\hline Variables & BMI & WC & DBP & SBP & Gluc & TG & $\mathrm{TC}$ & LDLc & HDLc & Leptin & Adipo. & Resi. \\
\hline \multicolumn{13}{|c|}{ All groups } \\
\hline BMI & 1 & & & & & & & & & & & \\
\hline WC & .142 & 1 & & & & & & & & & & \\
\hline DBP & .112 & .073 & 1 & & & & & & & & & \\
\hline SBP & $-.068-$ & $-.095-$ & .020 & 1 & & & & & & & & \\
\hline Gluco. & .035 & .153 & .077 & $.168^{*}$ & 1 & & & & & & & \\
\hline TG & .132 & .119 & .105 & .008 & $-.018-$ & 1 & & & & & & \\
\hline $\mathrm{TC}$ & .029 & $-.008-$ & .026 & .020 & $-.049-$ & $.296^{* *}$ & 1 & & & & & \\
\hline LDLc & $.256^{* *}$ & .114 & .151 & $-.027-$ & $.162^{*}$ & $.214^{* *}$ & $.306^{* *}$ & 1 & & & & \\
\hline HDLc & $-.074-$ & .060 & .001 & $-.105-$ & .074 & $-.109-$ & $-.210-^{* *}$ & .004 & 1 & & & \\
\hline Leptin & $.313^{* *}$ & $.276^{* *}$ & $.187^{*}$ & $-.008-$ & $.176^{*}$ & $.242^{* *}$ & $-.052-$ & $.182^{*}$ & $-.170-^{*}$ & 1 & & \\
\hline Adipo. & $-.232-^{* *}$ & $-.295-^{-* *}$ & $-.157-$ & .023 & -.089 & $-.377-{ }^{* *}$ & $-.094-$ & $-.2244^{* *}$ & $.216^{* *}$ & $-.595-^{* *}$ & 1 & \\
\hline Resistin & .051 & .051 & .052 & $.192-^{*}$ & $.135-$ & $.185^{*}$ & $.316^{* *}$ & .112 & $-.281^{* *}$ & .092 & $-.123-$ & 1 \\
\hline Visfatin & $.228^{* *}$ &. $.259^{* *}$ & .043 & .075 & $.182^{*}$ & $.283^{* *}$ & $-.032-$ & .088 & $-.144-$ & $.549^{* *}$ & $.506-^{* *}$ & .136 \\
\hline \multicolumn{13}{|c|}{ Healthy control group } \\
\hline BMI & 1 & & & & & & & & & & & \\
\hline WC & $-.224-$ & 1 & & & & & & & & & & \\
\hline DBP & .152 & $-.278-^{*}$ & 1 & & & & & & & & & \\
\hline SBP & $-.174-$ & $-.088-$ & .092 & 1 & & & & & & & & \\
\hline Gluco. & .022 & .053 & $-.017-$ & $-.017-$ & 1 & & & & & & & \\
\hline TG & $-.062-$ & .106 & .210 & .063 & .055 & 1 & & & & & & \\
\hline $\mathrm{TC}$ & $-.129-$ & $-.075-$ & $.426^{* *}$ & $-.038-$ & .034 & .030 & 1 & & & & & \\
\hline LDLc & $.254^{*}$ & $-.043-$ & .076 & .121 & .079 & .176 & .120 & 1 & & & & \\
\hline HDLc & $-.007-$ & .130 & $-.059-$ & $-.035-$ & $.315^{* *}$ & .108 & .163 & .197 & 1 & & & \\
\hline Leptin & $-.031-$ & .120 & $-.136-$ & .061 & $-.072-$ & $-.077-$ & $-.179-$ & $-.003-$ & .137 & 1 & & \\
\hline Adipone. & $-.038-$ & $-.054-$ & .089 & .176 & $-.115-$ & .043 & $-.147-$ & .065 & $-.008-$ & $-.002-$ & 1 & \\
\hline Resistin & $-.074-$ & $-.076-$ & $-.184-$ & .012 & $-.297-$ & $-.220-$ & $-.018-$ & $-.196-$ & .014 & $-.215-$ & .122 & 1 \\
\hline Visfatin & $-.126-$ & $-.201-$ & $-.019-$ & .015 & .050 & $-.085-$ & $-.014-$ & $-.310-^{*}$ & .085 & $-.016-$ & $-.024-$ & $-.008-$ \\
\hline
\end{tabular}

Adipo.: adiponectin; Gluco.: glucose. ${ }^{* *}$ Correlation is significant at the 0.01 level; ${ }^{*}$ correlation is significant at the 0.05 level. 
TABLE 4: Correlation of adipokines with TNM stages, tumor size, LN metastasis, and histological grading among postmenopausal and premenopausal BC.

\begin{tabular}{|c|c|c|c|c|c|c|c|}
\hline Variables & Leptin & Adipo. & Resistin & Visfatin & TNM & T. size & LN \\
\hline \multicolumn{8}{|c|}{ Postmenopausal BC } \\
\hline Leptin & 1 & & & & & & \\
\hline Adipo. & $-.566-^{* *}$ & 1 & & & & & \\
\hline Resistin & $-.435-^{* *}$ & $-.326-^{* *}$ & 1 & & & & \\
\hline Visfatin & $.627^{* *}$ & $-.597^{* *}$ & $.330^{*}$ & 1 & & & \\
\hline TNM & $.338^{*}$ & $-.264-^{*}$ & $.395^{*}$ & $.406^{* *}$ & 1 & & \\
\hline T. size & $.241^{*}$ & $-.725-^{* *}$ & $.429^{* *}$ & $.348^{*}$ & $.777^{* *}$ & 1 & \\
\hline $\mathrm{LN}$ & $.820^{* *}$ & $-.742-^{* *}$ & $.575^{* *}$ & $.529^{* *}$ & $.623^{* *}$ & $.633^{* *}$ & 1 \\
\hline Grade & $.762^{* *}$ & $-.682-^{* *}$ & $.509^{* *}$ & .132 & $.475^{* *}$ & $.780^{* *}$ & $.413^{* *}$ \\
\hline \multicolumn{8}{|c|}{ Premenopausal BC } \\
\hline Leptin & 1 & & & & & & \\
\hline Adipo. & .283 & 1 & & & & & \\
\hline Resistin & $-.143-$ & $-.017-$ & 1 & & & & \\
\hline Visfatin & .060 & $-.006-$ & .160 & 1 & & & \\
\hline TNM & .204 & $-.074-$ & .064 & .286 & 1 & & \\
\hline T. size & .062 & $-.164-$ & $-.081-$ & .292 & $.783^{* *}$ & 1 & \\
\hline $\mathrm{LN}$ & .247 & $-.152-$ & .010 & .177 & $.626^{* *}$ & $.580^{* *}$ & 1 \\
\hline Grade & .083 & $-.052-$ & $-.039-$ & .277 & $.551^{* *}$ & $.649^{* *}$ & $.341^{*}$ \\
\hline
\end{tabular}

${ }^{* *}$ Correlation is significant at the 0.01 level; ${ }^{*}$ correlation is significant at the 0.05 level.

$P=0.000)$. Serum visfatin levels showed positive significant correlations with BMI, WC, TG, and glucose $(r=0.288$, $P=0.005 ; r=0.259, P=0.001 ; r=0.283, P=0.000$; and $r=0.182, P=0.026)$. All the studied adipokines showed no significant correlations with the previous metabolic and anthropometric measurements among healthy control group $(P>0.05)$.

Table 4 depicts the correlations of serum adiponectin, leptin, resistin, and visfatin levels with clinicopathological features of pre- and postmenopausal BC patients. Leptin levels were positively correlated with TNM, tumor size, LN metastasis, and histological grading $(r=0.338, P=0.038$; $r=0.241, P=0.029 ; r=-0.820, P=0.000$; and $r=-0.762$, $P=0.000)$. Serum resistin levels also were positively correlated with TNM, tumor size, LN metastasis, and histological grading $(r=0.395, P=0.014 ; r=0.429, P=0.007 ; r=$ $0.575, P=0.000$; and $r=0.509, P=0.000)$. Serum visfatin showed positive correlations with TNM, tumor size, and LN metastasis $(r=0.406, P=0.000 ; r=0.348, P=0.028$; and $r=0.529, P=0.005)$. On the other hand, serum adiponectin levels correlated negatively with all clinicopathological $(P<$ $0.05)$ features and $r$ and $P$ values were shown in Table 4.

Among postmenopausal group multivariate logistic regression analysis, with the risk for $\mathrm{BC}$ as the dependent variable and adiponectin, leptin, resistin and visfatin, BMI, WC, TG, TC, HDLc, LDLc, and glucose as independent variables, showed that the variables including BMI, TG, adiponectin, leptin, visfatin, and resistin were accepted by the final model. The final model suggested that BMI, TG, adiponectin, leptin, visfatin, and resistin were risk factors for $\mathrm{BC}$, and the OR for BMI, TG, adiponectin, leptin, visfatin, and resistin was 0.370 (95\% CI: 1.004-4.278, $P=0.049$ ), 6.011
TABLE 5: Analysis of multivariate logistic regression with risk for BC as a dependent variable.

\begin{tabular}{lcccc}
\hline & $B$ & OR & $95 \%$ CI & $P$ value \\
\hline Adiponectin & -1.196 & 0.423 & $0.132-0.692$ & 0.005 \\
Leptin & 0.800 & 0.244 & $1.381-3.587$ & 0.001 \\
Resistin & 2.121 & 0.513 & $3.051-22.790$ & 0.000 \\
Visfatin & 0.250 & 1.089 & $1.062-1.116$ & 0.001 \\
BMI & 0.729 & 0.370 & $1.004-4.278$ & 0.049 \\
TG & 1.452 & 6.011 & $1.823-15.673$ & 0.004 \\
\hline
\end{tabular}

$P$ value significant at $P<0.05$.

(95\% CI: $1.823-15.673, P=0.004), 0.423$ (95\% CI: $0.132-$ 0.692, $P=0.005), 0.244$ (95\% CI: $1.381-3.587, P=0.001)$, 1.089 (95\% CI, 1.062-1.116; $P=0.001$ ), and 0.513 (95\% CI: 3.051-22.790, $P=0.000$ ), respectively (Table 5). In addition, the dependent variable was the risk for lymph node status (positive versus negative) and the same independent variables mentioned above were employed as independent variables. Resistin, leptin, and visfatin were accepted by the final model and the OR for them was 2.203 (95\% CI: 4.091-20.791, $P=$ 0.002 ), 0.742 (95\% CI: $1.504-2.921, P=0.003$ ), and 1.080 (95\% CI: 1.056-1.105; $P=0.003$ ), respectively (Table 6 ).

\section{Discussion}

$\mathrm{BC}$ is one of the most common cancers and a leading cause of cancer death in women worldwide. BC is a disease of aging and thus is more common in postmenopausal versus premenopausal women. There is substantial evidence that the 
TABLE 6: Analysis of multivariate logistic regression with risk for LN metastasis as a dependent variable.

\begin{tabular}{lcccc}
\hline & $B$ & OR & $95 \%$ CI & $P$ value \\
\hline Leptin & 0.874 & 0.742 & $1.504-2.921$ & 0.003 \\
Resistin & 1.452 & 2.203 & $4.091-20.791$ & 0.002 \\
Visfatin & 1.534 & 1.080 & $1.056-1.105$ & 0.003 \\
\hline
\end{tabular}

$P$ value significant at $P<0.05$.

risk of postmenopausal BC is increased for postmenopausal obese women [28]. Analyses of the recent data from a large number of cases revealed that higher body weight was linked with the occurrence of hormone receptor-positive tumors $[29,30]$. Obesity is an established risk factor for most hormone dependent cancers, including BC. The pathology underlying this phenomenon may be related to the endocrine and metabolic profile of this state. Recently researchers try to understand the link and underlying connection between obesity and BC. Studies focusing on adipocytokines and $\mathrm{BC}$ etiopathogenesis have shown that alterations in adipocytokines affect cell proliferation, apoptosis, tumor invasion, and angiogenesis [16]. In this study, we determined serum levels of leptin, adiponectin, resistin, and visfatin and we investigated the relation of those adipokines with other metabolic and anthropometric measurements to probe their relationship with risk of $\mathrm{BC}$ and other clinicopathological features. We also investigated the predictive role of those adipokines as regards their potential correlation and with clinicopathological features and anthropometric and metabolic parameters. Our results identified that there were statically higher serum levels of leptin, visfatin, and resistin and lower serum level of adiponectin in breast cancer patients compared to healthy controls.

Besides we demonstrated significant increase of leptin, visfatin, and resistin but significant decrease in adiponectin in postmenopausal $\mathrm{BC}$ when compared with postmenopausal control. There was also slight increase in levels of leptin, visfatin, and resistin in premenopausal $\mathrm{BC}$ cases in comparison to premenopausal controls. Regarding adiponectin levels, adiponectin levels were significantly lower only in postmenopausal BC not in premenopausal cancer subgroup compared to respected controls. Those findings were in agreement with other reports $[31,52]$. To date, the specific mechanism by which postmenopausal women, but not premenopausal women, have an obesity-related risk of $\mathrm{BC}$ has not been clarified. However, some studies mentioned the potential involvement of estrogens. It is well documented that the production of estrogen between premenopausal and postmenopausal women differs significantly. The main source of estrogen production in premenopausal women is the ovaries, whereas, for postmenopausal women, it is from peripheral adipose tissue $[27,33]$. In postmenopausal women, fat cells aromatize ovarian and adrenal androgens into estrogen. It has been demonstrated that elevated circulating levels of free estrogen, as well as estrone and androgens, are associated with BC [34]. Our data showed significantly elevated mean levels of serum TG, TC, LDLc, and reduced HDLc in all BC cases compared to healthy controls. Glucose levels were higher but not to significant value. Previous studies reported that high fasting glucose levels were directly correlated with BC both in premenopausal and postmenopausal women $[35,36]$. In addition, reduced HDLc and increased blood pressure contributed to increased risk for BC [37, 38]. Furthermore, it has been reported that low HDLc, hypertension, and hyperglycemia have all been associated with BC $[35,37,39$, 40].

We studied the association of different adipokines, metabolic as well as anthropometric parameters, and the risk of BC. Interestingly, only in postmenopausal subgroups we found significant associations between elevated levels of leptin, resistin, and visfatin, BMI, and TG of developing BC. Such association could not be found in premenopausal females. On the other hand, adiponectin had a protective effect with the risk of developing $\mathrm{BC}$ only in postmenopausal females. Previously, obesity was reported as a risk factor for postmenopausal BC $[4,22,41-44]$, whereas, in premenopausal women there is an inverse relation between BMI and BC risk $[45,46]$. Their results have indicated that this association may be partly explained by the high levels of circulating estrogen of their results for obese women. The adipose tissue of postmenopausal obese women secretes more biologically active estrogen which may stimulate mammary epithelial cell mitosis and promote the development of tumor [47]. Adipose tissue including intratumoral sites in breast tissue expresses aromatase enzyme that may play an important role in postmenopausal BC progression in relation to obesity status. It has been reported that hyperleptinemia enhanced aromatase activity resulting in increased synthesis of estrogens $[48,49]$. Leptin also has been reported to upregulate the expression of estrogen receptor- $\alpha(\mathrm{ER} \alpha)$ [50]. In contrast to our finding in premenopausal subgroups, a significant positive association between plasma leptin levels and premenopausal BC risk was reported [51]. Conversely, other retrospective studies have reported nonsignificant positive associations between leptin levels and premenopausal $\mathrm{BC}$ risk $[32,52,53]$. However, another study reported no association with premenopausal BC [54]. These conflicting results may partly be explained by the measurement of leptin after diagnosis, variation in sample sizes, varying level of control for confounders, differences in sample collection and measurement techniques, and heterogeneity of associations with pre- and postmenopausal BC.

We demonstrated that leptin, resistin, and visfatin might increase the risk of onset and lymph node metastasis of postmenopausal BC cases only and not in premenopausal BC group. In agreement with our results, Hou et al. [52] indicated that hyperleptinemia may be associated with $\mathrm{BC}$ especially with the onset and metastasis of $\mathrm{BC}$ after menopause, suggesting that hyperleptinemia may mediate the relationship between obesity and BC. Leptin has been reported to enhance aromatase activity in MCF-7 cell lines [55] which may enhance estrogen production and induce tumor cell growth [56]. Similarly, leptin receptors are expressed in T47-D BC cell lines and leptin induces proliferation of T47-D cells $[57,58]$. However, leptin may have the potential to reduce $\mathrm{BC}$ risk in premenopausal women [59], as it may play a role in ovarian folliculogenesis wherein at elevated levels 
it may reduce follicular estradiol secretion [60, 61]. Thus, postmenopausal female with elevated leptin levels could be at a reduced risk for $\mathrm{BC}$ due to leptin resistance with reduced leptin receptor activity [62]. We determined positive correlations of leptin, resistin, and visfatin and negative correlations of adiponectin with most of studied metabolic and anthropometric parameters including BMI, WC, TG, LDLc, and glucose in all studied groups. Also, in postmenopausal controls and cases there were positive correlation of leptin, resistin, and visfatin and negative correlations of adiponectin with TNM, tumor size, LN metastasis, and histological grade. Similarly, it was reported that serum leptin and resistin levels were positively associated with BMI and adiponectin is negatively correlated with BMI [52]. To our knowledge, both visfatin and resistin, as novel markers, have not been studied yet with adiponectin and leptin in relation to other anthropometric and metabolic parameters as risk factors for pre- and postmenopausal BC. Dalamaga et al. [22] hypothesized that visfatin, one of the measured adipokines in our study, by exhibiting proliferative, antiapoptotic, proinflammatory, and proangiogenic properties may be involved in the etiopathogenesis of postmenopausal BC and may represent a missing link between obesity and postmenopausal BC. Visfatin regulates and stimulates the proliferation and DNA synthesis rate of $\mathrm{BC}$ cells. It may contribute to $\mathrm{BC}$ pathogenesis by augmenting cell proliferation via stimulation of cell cycle progression and by increasing the expression of genes involved in angiogenesis and metastasis. Visfatin activates cell cycle progression by upregulation of cyclins and other cyclin-dependent kinases [63] and increases the synthesis of genes that play a significant role in tumorrelated angiogenesis such as vascular endothelium growth factor (VEGF), in metastasis and tumor invasion as matrix metalloproteases [64]. Their finding explains ours regarding visfatin. Visfatin levels were found to be predictor of LN metastasis in postmenopausal BC and were also positively associated with TNM staging and histological grade. On the other hand, resistin similarly may present a molecular link between inflammation and breast carcinogenesis. Expression of resistin was found to be upregulated during monocyte macrophage differentiation, indicating a role for resistin in monocyte-macrophage function [65-67]. In addition, resistin has been shown to exert potent proinflammatory properties by upregulating proinflammatory cytokines, probably via the NF- $\kappa \mathrm{B}$ pathway, suggesting a role for resistin in the process of inflammation [68]. In agreement with our results, Kang et al. [20] reported that serum resistin level was found to be significantly higher in the BC group than the control group, after adjustment for possible confounding variables such as BMI and serum glucose. Although resistin was first postulated to contribute to insulin resistance, it has recently been shown that resistin can trigger a proinflammatory state. As the evidence linking inflammation to $\mathrm{BC}$ risk grows $[69,70]$, nevertheless, our results must be interpreted in the context of the study design. When using a cross-sectional design, there is potential for selection bias, particularly in the selection of control groups. Our controls for either pre- or postmenopausal subgroups came from the same study base as our cases with breast cancers regarding age and BMI. Further classification of cases and controls into premenopausal and postmenopausal subgroups was carefully adjusted and exclusion was carried for any suspected subjects to cause any bias. However, important considerations were followed as follows: sample size being sufficient to generate statistically significant associations; the strict criteria for inclusion of case and control participants; the assessment of anthropometric, adipokines, and other parameters made using well-established and validated methods in the same laboratory and in a blinded fashion, which also eliminated uncontrolled confounding from these sources. However, the adjustment for many determinants of serum adipokines levels including inflammatory markers, insulin, and estrogen assessment may be suggested to reinforce the observed associations in our future research.

\section{Conclusion}

The results suggested a possibility that the serum resistin, leptin, adiponectin, and visfatin levels could be considered risk factors for BC. They could provide a potential link for the association between obesity and $\mathrm{BC}$ risk promising to be of diagnostic value for postmenopausal BC.

\section{Conflict of Interests}

The authors declare that they have no conflict of interests.

\section{Acknowledgment}

This study was supported by a grant from Institute of Scientific Research and Revival of Islamic Heritage at Umm Al-Qura University, Makkah, KSA (Project no. 43309028).

\section{References}

[1] S. Loi, R. L. Milne, M. L. Friedlander et al., "Obesity and outcomes in premenopausal and postmenopausal breast cancer," Cancer Epidemiology Biomarkers \& Prevention, vol. 14, no. 7, pp. 1686-1691, 2005.

[2] G. A. Porter, K. M. Inglis, L. A. Wood, and P. J. Veugelers, "Effect of obesity on presentation of breast cancer," Annals of Surgical Oncology, vol. 13, no. 3, pp. 327-332, 2006.

[3] S. C. Newman, A. W. Lees, and H. J. Jenkins, "The effect of body mass index and oestrogen receptor level on survival of breast cancer patients," International Journal of Epidemiology, vol. 26, no. 3, pp. 484-490, 1997.

[4] M. Harvie, L. Hooper, and A. H. Howell, "Central obesity and breast cancer risk: a systematic review," Obesity Reviews, vol. 4, no. 3, pp. 157-173, 2003.

[5] G. Fantuzzi, "Adipose tissue, adipokines, and inflammation," Journal of Allergy and Clinical Immunology, vol. 115, no. 5, pp. 911-920, 2005.

[6] H. Tilg and A. R. Moschen, "Adipocytokines: mediators linking adipose tissue, inflammation and immunity," Nature Reviews Immunology, vol. 6, no. 10, pp. 772-783, 2006.

[7] L. Vona-Davis and D. P. Rose, "Adipokines as endocrine, paracrine, and autocrine factors in breast cancer risk and progression," Endocrine-Related Cancer, vol. 14, no. 2, pp. 189206, 2007. 
[8] A. Schäffler, J. Schölmerich, and C. Buechler, "Mechanisms of disease: adipokines and breast cancer-endocrine and paracrine mechanisms that connect adiposity and breast cancer," Nature Clinical Practice Endocrinology and Metabolism, vol. 3, no. 4, pp. 345-354, 2007.

[9] S. Perrier, F. Caldefie-Chézet, and M.-P. Vasson, "IL-1 family in breast cancer: potential interplay with leptin and other adipocytokines," FEBS Letters, vol. 583, no. 2, pp. 259-265, 2009.

[10] S. S. Tworoger, A. H. Eliassen, T. Kelesidis et al., "Plasma adiponectin concentrations and risk of incident breast cancer," Journal of Clinical Endocrinology and Metabolism, vol. 92, no. 4, pp. 1510-1516, 2007.

[11] K. G. M. M. Alberti, P. Zimmet, and J. Shaw, "Metabolic syndrome-a new world-wide definition. A Consensus Statement from the International Diabetes Federation," Diabetic Medicine, vol. 23, no. 5, pp. 469-480, 2006.

[12] X. Hu, S. C. Juneja, N. J. Maihle, and M. P. Cleary, "Leptina growth factor in normal and malignant breast cells and for normal mammary gland development," Journal of the National Cancer Institute, vol. 94, no. 22, pp. 1704-1711, 2002.

[13] C. Garofalo and E. Surmacz, "Leptin and cancer," Journal of Cellular Physiology, vol. 207, no. 1, pp. 12-22, 2006.

[14] A. Eisenberg, E. Biener, M. Charlier et al., "Transactivation of erbB2 by short and long isoforms of leptin receptors," FEBS Letters, vol. 565, no. 1-3, pp. 139-142, 2004.

[15] S. Catalano, L. Mauro, S. Marsico et al., "Leptin induces, via ERK1/ERK2 signal, functional activation of estrogen receptor alpha in MCF-7 cells," Journal of Biological Chemistry, vol. 279, no. 19, pp. 19908-19915, 2004.

[16] I. Kelesidis, T. Kelesidis, and C. S. Mantzoros, "Adiponectin and cancer: a systematic review," British Journal of Cancer, vol. 94, no. 9, pp. 1221-1225, 2006.

[17] E. E. Kershaw and J. S. Flier, "Adipose tissue as an endocrine organ," Journal of Clinical Endocrinology and Metabolism, vol. 89, no. 6, pp. 2548-2556, 2004.

[18] C. Mantzoros, E. Petridou, N. Dessypris et al., "Adiponectin and breast cancer risk," The Journal of Clinical Endocrinology and Metabolism, vol. 89, no. 3, pp. 1102-1107, 2004.

[19] C. M. Steppan, S. T. Bailey, S. Bhat et al., "The hormone resistin links obesity to diabetes," Nature, vol. 409, no. 6818, pp. 307-312, 2001.

[20] J.-H. Kang, B.-Y. Yu, and D.-S. Youn, "Relationship of serum adiponectin and resistin levels with breast cancer risk," Journal of Korean Medical Science, vol. 22, no. 1, pp. 117-121, 2007.

[21] A. R. Moschen, R. R. Gerner, and H. Tilg, "Pre-B cell colony enhancing factor/Nampt/visfatin in inflammation and obesityrelated disorders," Current Pharmaceutical Design, vol. 16, no. 17, pp. 1913-1920, 2010.

[22] M. Dalamaga, K. Karmaniolas, E. Papadavid, N. Pelekanos, G. Sotiropoulos, and A. Lekka, "Elevated serum visfatin/nicotinamide phosphoribosyl-transferase levels are associated with risk of postmenopausal breast cancer independently from adiponectin, leptin, and anthropometric and metabolic parameters," Menopause, vol. 18, no. 11, pp. 1198-1204, 2011.

[23] Y.-C. Lee, Y.-H. Yang, J.-H. Su, H.-L. Chang, M.-F. Hou, and S.-S. F. Yuan, "High visfatin expression in breast cancer tissue is associated with poor survival," Cancer Epidemiology Biomarkers and Prevention, vol. 20, no. 9, pp. 1892-1901, 2011.

[24] T. J. Key, P. K. Verkasalo, and E. Banks, "Epidemiology of breast cancer," Lancet Oncology, vol. 2, no. 3, pp. 133-140, 2001.
[25] R. E. James, A. Lukanova, L. Dossus et al., "Postmenopausal serum sex steroids and risk of hormone receptor-positive and -negative breast cancer: a nested case-control study," Cancer Prevention Research, vol. 4, no. 10, pp. 1626-1635, 2011.

[26] S. W. Oh, C.-Y. Park, E. S. Lee et al., "Adipokines, insulin resistance, metabolic syndrome, and breast cancer recurrence: a cohort study," Breast Cancer Research, vol. 13, no. 2, article R34, 2011.

[27] E. E. Calle and R. Kaaks, "Overweight, obesity and cancer: epidemiological evidence and proposed mechanisms," Nature Reviews Cancer, vol. 4, no. 8, pp. 579-591, 2004.

[28] A. Ray and M. P. Cleary, "Obesity and breast cancer: a clinical biochemistry perspective," Clinical Biochemistry, vol. 45, no. 3, pp. 189-197, 2012.

[29] A. Vrieling, K. Buck, R. Kaaks, and J. Chang-Claude, "Adult weight gain in relation to breast cancer risk by estrogen and progesterone receptor status: a meta-analysis," Breast Cancer Research and Treatment, vol. 123, no. 3, pp. 641-649, 2010.

[30] X. R. Yang, J. Chang-Claude, E. L. Goode et al., "Associations of breast cancer risk factors with tumor subtypes: a pooled analysis from the Breast Cancer Association consortium studies," Journal of the National Cancer Institute, vol. 103, no. 3, pp. 250-263, 2011.

[31] C.-A. Sun, M.-H. Wu, C.-H. Chu et al., "Adipocytokine resistin and breast cancer risk," Breast Cancer Research and Treatment, vol. 123, no. 3, pp. 869-876, 2010.

[32] K. B. Michels, K. L. Terry, and W. C. Willett, "Longitudinal study on the role of body size in premenopausal breast cancer," Archives of Internal Medicine, vol. 166, no. 21, pp. 2395-2402, 2006.

[33] P. K. Siiteri, "Adipose tissue as a source of hormones," American Journal of Clinical Nutrition, vol. 45, no. 1, supplement, pp. 277282, 1987.

[34] A. McTiernan, "Associations between energy balance and body mass index and risk of breast carcinoma in women from diverse racial and ethnic backgrounds in the United States," Cancer, vol. 88 , supplement 5, pp. 1248-1255, 2000.

[35] P. Muti, T. Quattrin, B. J. B. Grant et al., "Fasting glucose is a risk factor for breast cancer: a prospective study," Cancer Epidemiology Biomarkers and Prevention, vol. 11, no. 11, pp. 13611368, 2002.

[36] K. Rapp, J. Schroeder, J. Klenk et al., "Fasting blood glucose and cancer risk in a cohort of more than 140,000 adults in Austria," Diabetologia, vol. 49, no. 5, pp. 945-952, 2006.

[37] A.-S. Furberg, M. B. Veierød, T. Wilsgaard, L. Berstein, and I. Thune, "Serum high density lipoprotein cholesterol, metabolic profile, and breast cancer risk," Journal of the National Cancer Institute, vol. 96, no. 15, pp. 1152-1160, 2004.

[38] M. Soler, L. Chatenoud, E. Negri, F. Parazzini, S. Franceschi, and C. La Vecchia, "Hypertension and hormone-related neoplasms in women," Hypertension, vol. 34, no. 2, pp. 320-325, 1999.

[39] P. H. M. Peeters, P. A. H. van Noord, A. W. Hoes, J. Fracheboud, C. H. F. Gimbrère, and D. E. Grobbee, "Hypertension and breast cancer risk in a 19-year follow-up study (the DOM cohort). Diagnostic investigation into mammarian cancer," Journal of Hypertension, vol. 18, no. 3, pp. 249-254, 2000.

[40] Y. M. Chong, S. L. J. Williams, A. Elkak, A. K. Sharma, and K. Mokbel, "Insulin-like growth factor 1 (IGF-1) and its receptor mRNA levels in breast cancer and adjacent non-neoplastic tissue," Anticancer Research, vol. 26, pp. 167-173, 2006. 
[41] L. M. Morimoto, E. White, Z. Chen et al., "Obesity, body size, and risk of postmenopausal breast cancer: the women's health initiative (United States)," Cancer Causes and Control, vol. 13, no. 8, pp. 741-751, 2002.

[42] J. Ahn, A. Schatzkin, J. V. Lacey Jr. et al., "Adiposity, adult weight change, and postmenopausal breast cancer risk," Archives of Internal Medicine, vol. 167, no. 19, pp. 2091-2102, 2007.

[43] P. H. Lahmann, K. Hoffmann, N. Allen et al., "Body size and breast cancer risk: findings from the European Prospective Investigation into Cancer and Nutrition (EPIC)," International Journal of Cancer, vol. 111, no. 5, pp. 762-771, 2004.

[44] C. I. Li, K. E. Malone, and J. R. Daling, "Interactions between body mass index and hormone therapy and postmenopausal breast cancer risk (United States)," Cancer Causes and Control, vol. 17, no. 5, pp. 695-703, 2006.

[45] J. R. Daling, K. E. Malone, D. R. Doody, L. G. Johnson, J. R. Gralow, and P. L. Porter, "Relation of body mass index to tumor markers and survival among young women with invasive ductal breast carcinoma," Cancer, vol. 92, no. 4, pp. 720-729, 2001.

[46] S. Rinaldi, T. J. Key, P. H. M. Peeters et al., "Anthropometric measures, endogenous sex steroids and breast cancer risk in postmenopausal women: a study within the EPIC cohort," International Journal of Cancer, vol. 118, no. 11, pp. 2832-2839, 2006.

[47] D.-F. Han, X. Zhou, M.-B. Hu et al., "Polymorphisms of estrogen-metabolizing genes and breast cancer risk: a multigenic study," Chinese Medical Journal, vol. 118, no. 18, pp. 15071516, 2005.

[48] D. A. Magoffin, S. R. Weitsman, S. K. Aagarwal, and A. J. Jakimiuk, "Leptin regulation of aromatase activity in adipose stromal cells from regularly cycling women," Ginekologia Polska, vol. 70, no. 1, pp. 1-7, 1999.

[49] J. Geisler, B. Haynes, D. Ekse, M. Dowsett, and P. E. Lønning, "Total body aromatization in postmenopausal breast cancer patients is strongly correlated to plasma leptin levels," Journal of Steroid Biochemistry and Molecular Biology, vol. 104, no. 1-2, pp. 27-34, 2007.

[50] W. Yu, J.-C. Gu, J.-Z. Liu et al., "Regulation of estrogen receptors $\alpha$ and $\beta$ in human breast carcinoma by exogenous leptin in nude mouse xenograft model," Chinese Medical Journal, vol. 123, no. 3, pp. 337-343, 2010.

[51] L. Tessitore, B. Vizio, D. Pesola et al., "Adipocyte expression and circulating levels of leptin increase in both gynaecological and breast cancer patients," International journal of oncology, vol. 24, no. 6, pp. 1529-1535, 2004.

[52] W.-K. Hou, Y.-X. Xu, T. Yu et al., "Adipocytokines and breast cancer risk," Chinese Medical Journal, vol. 120, no. 18, pp. 15921596, 2007.

[53] C.-L. Liu, Y.-C. Chang, S.-P. Cheng et al., “The roles of serum leptin concentration and polymorphism in leptin receptor gene at codon 109 in breast cancer," Oncology, vol. 72, no. 1-2, pp. 7581, 2007.

[54] C. S. Mantzoros, K. Bolhke, S. Moschos, and D. W. Cramer, "Leptin in relation to carcinoma in situ of the breast: a study of pre-menopausal cases and controls," International Journal of Cancer, vol. 80, no. 4, pp. 523-526, 1999.

[55] M. Okumura, M. Yamamoto, H. Sakuma et al., "Leptin and high glucose stimulate cell proliferation in MCF-7 human breast cancer cells: reciprocal involvement of PKC- $\alpha$ and PPAR expression," Biochimica et Biophysica Acta-Molecular Cell Research, vol. 1592, no. 2, pp. 107-116, 2002.
[56] S. Catalano, S. Marsico, C. Giordano et al., "Leptin enhances, via AP-1, expression of aromatase in the MCF-7 cell line," The Journal of Biological Chemistry, vol. 278, no. 31, pp. 2866828676, 2003.

[57] S. N. O'Brien, B. H. Welter, and T. M. Price, "Presence of leptin in breast cell lines and breast tumors," Biochemical and Biophysical Research Communications, vol. 259, no. 3, pp. 695698, 1999.

[58] K. Laud, I. Gourdou, L. Pessemesse, J. P. Peyrat, and J. Djiane, "Identification of leptin receptors in human breast cancer: functional activity in the T47-D breast cancer cell line," Molecular and Cellular Endocrinology, vol. 188, no. 1-2, pp. 219-226, 2002.

[59] H. R. Harris, S. S. Tworoger, S. E. Hankinson, B. A. Rosner, and K. B. Michels, "Plasma leptin levels and risk of breast cancer in premenopausal women," Cancer Prevention Research, vol. 4, no. 9, pp. 1449-1456, 2011.

[60] J. D. Brannian and K. A. Hansen, "Leptin and ovarian folliculogenesis: implications for ovulation induction and ART outcomes," Seminars in Reproductive Medicine, vol. 20, no. 2, pp. 103-112, 2002.

[61] R. T. Falk, L. A. Brinton, M. P. Madigan et al., "Interrelationships between serum leptin, IGF-1, IGFBP3, C-peptide and prolactin and breast cancer risk in young women," Breast Cancer Research and Treatment, vol. 98, no. 2, pp. 157-165, 2006.

[62] P. J. Scarpace and Y. Zhang, "Leptin resistance: a prediposing factor for diet-induced obesity," The American Journal of Physiology-Regulatory Integrative and Comparative Physiology, vol. 296, no. 3, pp. R493-R500, 2009.

[63] J. G. Kim, E. O. Kim, B. R. Jeong et al., "Visfatin stimulates proliferation of MCF-7 human breast cancer cells," Molecules and Cells, vol. 30, no. 4, pp. 341-345, 2010.

[64] S. T. Patel, T. Mistry, J. E. P. Brown et al., "A novel role for the adipokine visfatin/pre-B cell colony-enhancing factor 1 in prostate carcinogenesis," Peptides, vol. 31, no. 1, pp. 51-57, 2010.

[65] D. B. Savage, C. P. Sewter, E. S. Klenk et al., "Resistin/Fizz3 expression in relation to obesity and peroxisome proliferatoractivated receptor-gamma action in humans," Diabetes, vol. 50, no. 10, pp. 2199-2202, 2001.

[66] L. Patel, A. C. Buckels, I. J. Kinghorn et al., "Resistin is expressed in human macrophages and directly regulated by PPAR $\gamma$ activators," Biochemical and Biophysical Research Communications, vol. 300, no. 2, pp. 472-476, 2003.

[67] M. Filkova, M. Haluzik, S. Gay, and L. Senolt, "The role of resistin as a regulator of inflammation: implications for various human pathologies," Clinical Immunology, vol. 133, no. 2, pp. 157-170, 2009.

[68] C. Bertolani, P. Sancho-Bru, P. Failli et al., "Resistin as an intrahepatic cytokine: overexpression during chronic injury and induction of proinflammatory actions in hepatic stellate cells," The American Journal of Pathology, vol. 169, no. 6, pp. 2042-2053, 2006.

[69] R. E. Harris, R. T. Chlebowski, R. D. Jackson et al., "Breast cancer and nonsteroidal anti-inflammatory drugs: prospective results from the Women's Health Initiative," Cancer Research, vol. 63, no. 18, pp. 6096-6101, 2003.

[70] L. A. Hefler, C. Grimm, T. Lantzsch et al., "Interleukin-1 and interleukin- 6 gene polymorphisms and the risk of breast cancer in Caucasian women," Clinical Cancer Research, vol. 11, no. 16, pp. 5718-5721, 2005. 


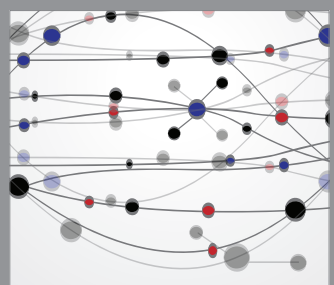

The Scientific World Journal
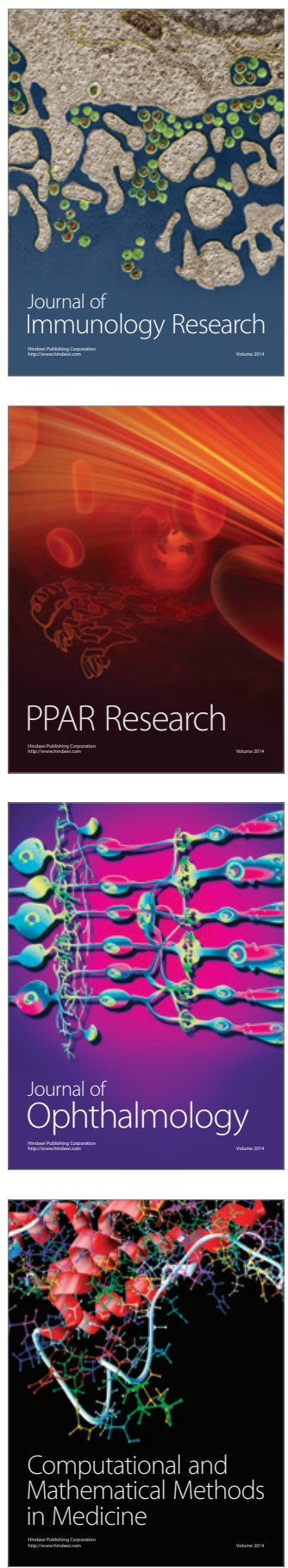

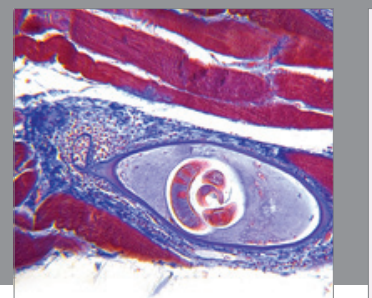

Gastroenterology

Research and Practice
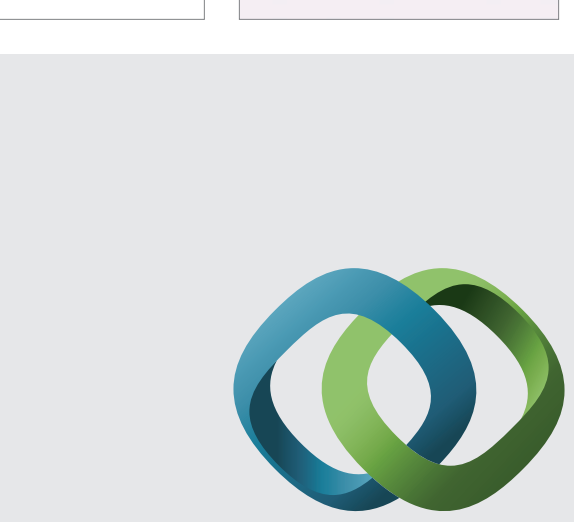

\section{Hindawi}

Submit your manuscripts at

http://www.hindawi.com
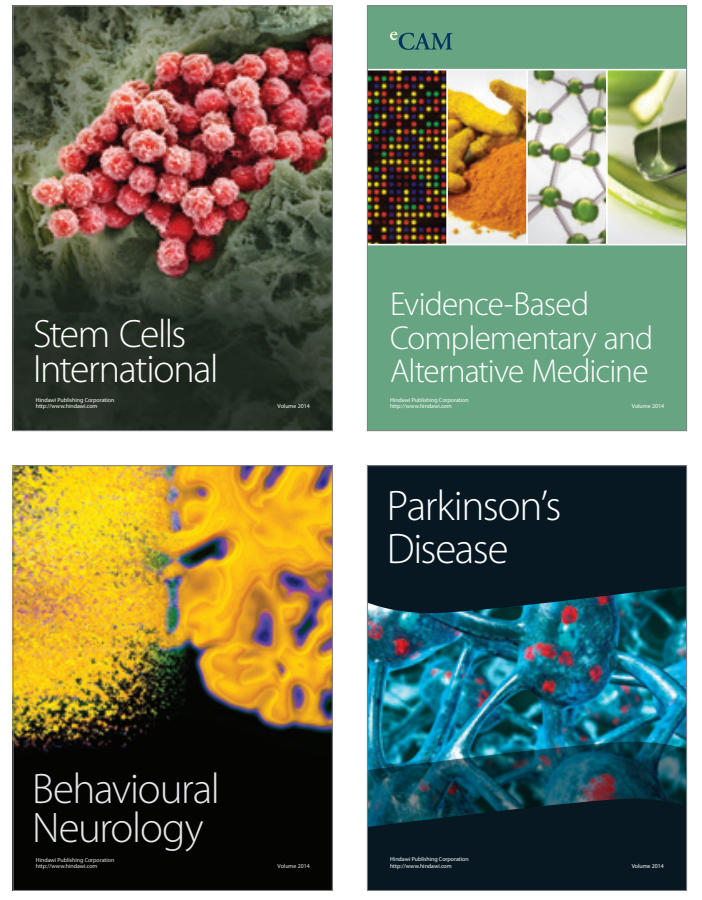
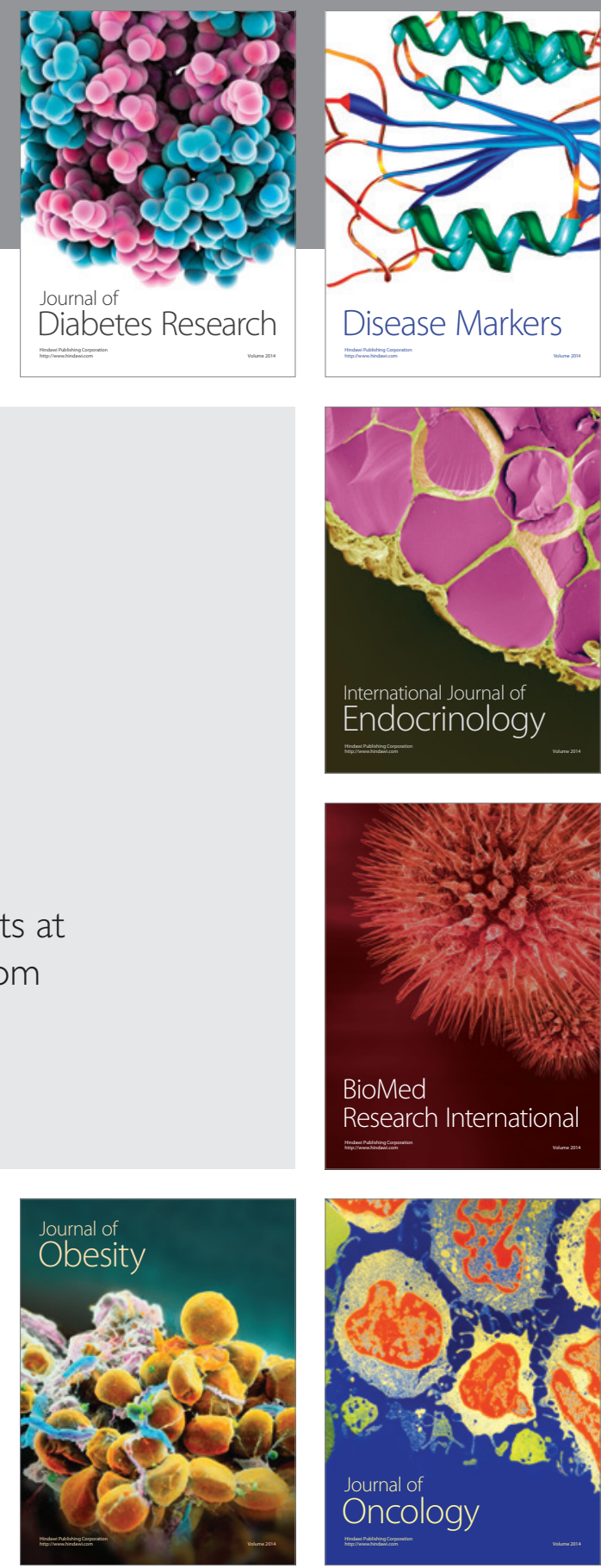

Disease Markers
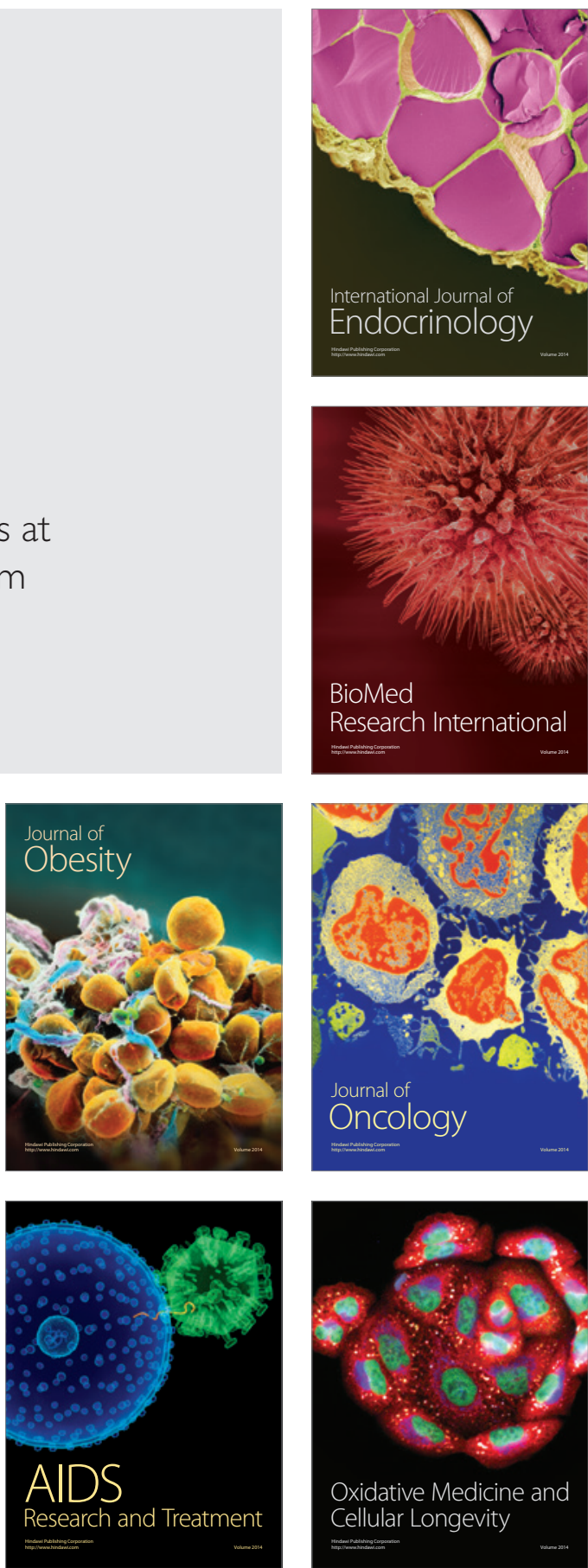